
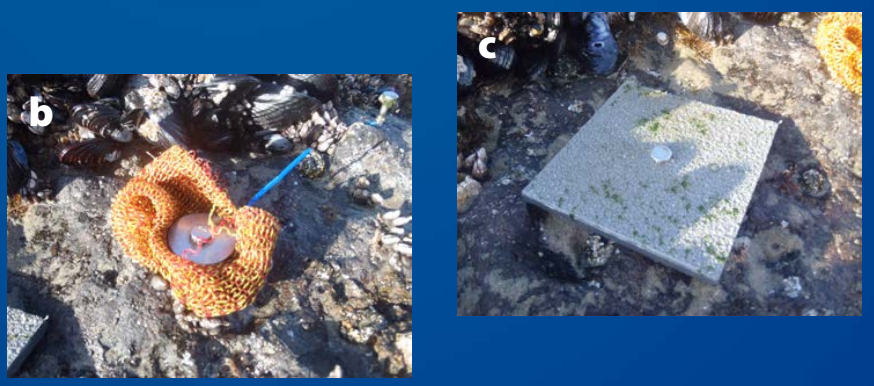

Examples of standardized larval collectors. (a) A PISCO diver retrieves a moored "SMURF" (Standardized Monitoring Unit for Reef Fishes) to sample kelp forest fish larvae. (b) A kitchen scrubber "tuffy" is used to sample settling larval mussels. (c) A ceramic tile samples settling larval barnacles. (d) PISCO scientists deploy tuffies and plates in the intertidal zone. Photo credits: J. Figurski (a), J. Robinson (b,c), and B. Poirson (d)

\title{
SIDEBAR. Empirical Approaches to Measure Connectivity
}

By J. Wilson White, Mark H. Carr, Jennifer E. Caselle, Stephen R. Palumbi, Robert R. Warner, Bruce A. Menge, and Kristen Milligan

It is logistically difficult to directly tag larvae to track their dispersal over large spatial scales (the rare exception is work done by Jones et al., 2005), so a variety of approaches have been developed to measure connectivity processes indirectly or passively. When the Partnership for Interdisciplinary Studies of Coastal Oceans (PISCO) began in 1999, a sea change was underway in our understanding of larval connectivity: after decades of assuming that larval dispersal was widespread and that larvae rained down to the benthos from a well-mixed pool, new tools and new evidence suggested the potential for much shorter dispersal distances and considerable retention of larvae near spawning sites (see White et al., 2019, in this issue). In the subsequent two decades, PISCO scientists have used a variety of empirical and modeling tools to understand connectivity patterns. Some of these have evolved in complexity with the advent of new techniques and greater computing power (genomics, biophysical models), while others have proven to be less fruitful than originally hoped (natural markers in calcified structures). Here, we describe some of these tools.

\section{Genetic Methods}

Dispersal inferences based on genetic differences between populations integrate over many individuals and many generations, and may not reflect contemporary gene flow if dispersal dynamics have changed (Waples, 1998). However, new genomic tools can reveal the geographic distribution of thousands of gene loci among populations, instead of the handfuls of loci that were used in decades past. Analyzing a large number of loci allows much finer detection of subtle patterns of gene flow, revealing barriers to dispersal and detecting loci that are under active selection in different environments (Marko and Hart, 2018). This is a doubleedged sword because strong selection after settlement can limit gene flow, even in the absence of barriers to dispersal. As a result, a genetic difference between populations may not signal lack of dispersal but instead signal a different habitat, selecting for differ- ent traits. This possibility must be accounted for when interpreting genetic data.

Richer data sets also allow detection of close kin in marine populations, sometimes even parent/offspring pairs (e.g., parentage analysis), strengthening our ability to quantify dispersal events over ecological time scales (e.g., D’Aloia et al., 2015; Almany et al., 2017). These can also help measure current population sizes through a type of genetic recapture analysis (e.g., Hillary et al., 2018). A different type of kinship, sibling-ship, has also been increasingly detected with unexpected frequency in larval cohorts settling at the same location. This can provide evidence that larvae spawned together may travel together in coherent "packets" (Selkoe et al., 2006).

Information from genetics can be generalized into a description of connectivity in the metapopulation. Often this takes the form of a dispersal kernel, a statistical description of the probability of a larva traveling a given distance and direction from its source. Bode et al. (2018) provide guidance on how to avoid some of the conceptual pitfalls in using this method.

\section{Biophysical Models}

An increasingly widespread approach to estimating connectivity computationally is to simulate the release of "larvae" as particles in the flow field produced by a three-dimensional numerical ocean circulation model (e.g., Shchepetkin and McWilliams, 2005). As the data sets required to drive such models have become more widely available and computational power has increased, it has become possible to generate connectivity estimates for nearly any area of interest. The advantage of such models is that they can generate dispersal probabilities over large spatial scales at high resolution, without depending on intensive collection of individual parents and settlers. However, there are three major limitations. First, predictions depend on the specified behavior of the simulated larvae (Paris et al., 2007), but in many cases we know 
little about the ontogeny of depth regulation and swimming in larvae. Second, many species of interest reside in shallow nearshore waters, where it is difficult for models to faithfully represent circulation (though this is an active area of research; Kumar et al., 2015). Finally, it is difficult to validate dispersal predictions, because we usually lack information on where and how many larvae are spawned at any given time, and thus how many should be predicted to disperse. However, this comparison has been made successfully in a few cases (e.g., Watson et al., 2010).

\section{Natural and Artificial Markers in Calcified Structures}

Many species lay down daily rings of calcium carbonate in their otoliths (fish "ear stones") or statoliths (invertebrate "equilibrium stones"), preserving a time-stamped record of age, growth, and trace element signatures from the surrounding water. Because there is geographical variation in oceanic trace element concentrations, there exists the intriguing possibility of extracting timestamped spatial information from calcified structures and determining the origin or transport pathway of larvae. The idea is that one could map connectivity pathways by comparing the trace element signatures in the core region of the otolith or the statolith of a post-dispersal recruit to the geographic pattern (an "atlas") of trace element signatures in pre-dispersal young. Unfortunately, the spatial resolution of such an atlas is usually quite coarse and can vary over time. Consequently, this approach has only been deployed successfully to estimate a full set of connectivity pathways for coastal or open-ocean species in a few cases, using bivalves (e.g., Becker et al., 2007). Other applications have provided more limited information on connectivity, such as the proportion of settling larvae produced locally vs. elsewhere (e.g., Hamilton et al., 2008).

\section{Standardized Recruitment Monitoring}

Large-scale, long-term monitoring of larval settlement across multiple sites can reveal the physical factors affecting nearshore larval delivery, and also facilitates comparisons with model predictions (e.g., Watson et al., 2010). Such monitoring requires standardized, easily deployable, inexpensive, and readily processable samples of larval propagule supply. The basic approach is to artificially mimic natural settlement substrate-from flat plates to filamentous mussel byssal threads to artificial kelp canopy-and PISCO has used this approach to develop standardized larval monitoring devices for mussels, sea urchins, sea stars, crabs, and fishes (see photos on opposite page). In all these cases, the goal is to provide homogeneity in collection method to facilitate comparisons over time and space. One caveat to these approaches is the concern that these devices could conceivably produce biased settlement estimates, because of either different attractiveness or different post-settlement mortality relative to natural habitats. Also, patterns of larval abundance and patterns of connectivity are not always perfectly linked, because abundance depends on patterns of larval production as well as larval delivery (Watson et al., 2010). However, it appears to be safe to use these as relative indices of larval delivery for the purposes of detecting longterm, large-scale patterns. ¿c

\section{REFERENCES}

Almany, G.R., S. Planes, S.R. Thorrold, M.L. Berumen, M. Bode, P. Saenz-Agudelo, M.C. Bonin, A.J. Frisch, H.B. Harrison, V. Messmer, and others. 2017. Larval fish dispersal in a coral-reef seascape. Nature Ecology and Evolution 1:0148, https://doi.org/10.1038/s41559-017-0148.
Becker, B.J., L.A. Levin, F.J. Fodrie, and P.A. McMillan. 2007. Complex larval connectivity patterns among marine invertebrate populations. Proceedings of the National Academy of Sciences of the United States of America 104:3,267-3,272, https://doi.org/10.1073/pnas.0611651104.

Bode, M., D.H. Williamson, H.B. Harrison, N. Outram, and G.P. Jones. 2018. Estimating dispersal kernels using genetic parentage data. Methods in Ecology and Evolution 9:490-501, https://doi.org/10.1111/2041-210X.12922.

D’Aloia, C.C., S.M. Bogdanowicz, R.K. Francis, J.E. Majoris, R.G. Harrison, and P.M. Buston. 2015. Patterns, causes, and consequences of marine larval dispersal. Proceedings of the National Academy of Sciences of the United States of America 112:13,940-13,945, https://doi.org/10.1073/pnas.1513754112.

Hamilton, S.L., J. Regetz, and R.R. Warner. 2008. Postsettlement survival linked to larval life in a marine fish. Proceedings of the National Academy of Sciences of the United States of America 105:1,561-1,566, https://doi.org/10.1073/ pnas.0707676105.

Hillary, R.M., M.V. Bravington, T.A. Patterson, P. Grewe, R. Bradford, P. Feutry, R. Gunasekera, V. Peddemors. J. Werry, M.P. Francis, and others. 2018. Genetic relatedness reveals total population size of white sharks in eastern Australia and New Zealand. Scientific Reports 8:2661, https://doi.org/10.1038/ s41598-018-20593-W.

Jones, G.P., S. Planes, and S.R. Thorrold. 2005. Coral reef fish larvae settle close to home. Current Biology 15:1,314-1,318, https://doi.org/10.1016/j.cub.2005.06.061.

Kumar, N., F. Federson, Y. Uchiyama, J. McWilliams, and W. O'Reilly. 2015. Midshelf to surfzone coupled ROMS-SWAN model data comparison of waves, currents, and temperature: Diagnosis of subtidal forcings and response. Journal of Physical Oceanography 45:1,464-1,490, https://doi.org/10.1175/JPO-D-14-0151.1.

Marko, P.B., and M.W. Hart. 2018. Genetic analysis of larval dispersal, gene flow, and connectivity. Pp. 165-166 in Evolutionary Ecology of Marine Invertebrate Larvae. T. Carrier, A. Reitzel, and A. Heyland, eds, Oxford University Press, Oxford, UK, https://doi.org/10.1093/oso/9780198786962.003.0012.

Paris, C.B., L.M. Chérubin, and R.K. Cowen. 2007. Surfing, spinning, or diving from reef to reef: Effects on population connectivity. Marine Ecology Progress Series 347:285-300, https://doi.org/10.3354/meps06985.

Shchepetkin, A.F., and J.C. McWilliams. 2005. The regional oceanic modeling system (ROMS): A split-explicit, free-surface, topography-followingcoordinate oceanic model. Ocean Modelling 9:347-404, https://doi.org/10.1016/ j.ocemod.2004.08.002.

Selkoe, K.A., S.D. Gaines, J.E. Caselle, and R.R. Warner. 2006. Current shifts and kin aggregation explain genetic patchiness in fish recruits. Ecology 87:3,082-3,094.

Waples, R.S. 1998. Separating the wheat from the chaff: Patterns of genetic differentiation in high gene flow species. Journal of Heredity 89:438-450, https://doi.org/10.1093/jhered/89.5.438.

Watson, J.R., S. Mitarai, D.A. Siegel, J.E. Caselle, C. Dong, and J.C. McWilliams. 2010. Realized and potential larval connectivity in the Southern California Bight. Marine Ecology Progress Series 401:31-48, https://doi.org/10.3354/meps08376. White, J.W., M.H. Carr, J.E. Caselle, L. Washburn, C.B. Woodson, S.R. Palumbi, P.M. Carlson, R.R. Warner, B.A. Menge, J.A. Barth, and others. 2019. Connectivity, dispersal, and recruitment: Connecting benthic communities and the coastal ocean. Oceanography 32(3):50-59, https://doi.org/10.5670/oceanog.2019.310.

\section{ACKNOWLEDGMENTS}

We thank the David and Lucile Packard Foundation for ongoing support. This is contribution 493 from PISCO, the Partnership for Interdisciplinary Studies of Coastal Oceans.

\section{AUTHORS}

J.Wilson White (will.white@oregonstate.edu) is Assistant Professor, Coastal Oregon Marine Experiment Station, Oregon State University, Newport, OR, USA. Mark H. Carr is Professor, Department of Ecology and Evolutionary Biology, University of California, Santa Cruz, CA, USA. Jennifer E. Caselle is Research Biologist, Marine Science Institute, University of California, Santa Barbara, CA, USA. Stephen R. Palumbi is Professor, Department of Biology, Stanford University, Stanford, CA, USA. Robert R. Warner is Research Professor, Department of Ecology, Evolution, and Marine Biology, University of California, Santa Barbara, CA, USA. Bruce A. Menge is Professor, Department of Integrative Biology, Oregon State University, Corvallis, OR, USA. Kristen Milligan is Associate Director, Marine Studies Initiative at Oregon State University, and previously PISCO Program Coordinator, Corvallis, OR, USA.

\section{ARTICLE CITATION}

White, J.W., M.H. Carr, J.E. Caselle, S.R. Palumbi, R.R. Warner, B.A. Menge, and K. Milligan. 2019. Empirical approaches to measure connectivity. Oceanography 32(3):60-61, https://doi.org/10.5670/oceanog.2019.311.

\section{COPYRIGHT \& USAGE}

This is an open access article made available under the terms of the Creative Commons Attribution 4.0 International License (https://creativecommons.org/ licenses/by/4.0/), which permits use, sharing, adaptation, distribution, and reproduction in any medium or format as long as users cite the materials appropriately, provide a link to the Creative Commons license, and indicate the changes that were made to the original content. 